\title{
A NEUROPHARMACOLOGICALLY ACTIVE SUBSTANCE FROM JELLYFISH GANGLIA
}

\author{
By W. J. P. BARNES AND G. A. HORRIDGE \\ Gatty Marine Laboratory and Department of Natural History, \\ University of St Andrezos \\ (Received 30 Fune 1964) \\ INTRODUCTION
}

For three main reasons there is almost no information on possible transmitter substances of coelenterates. Animals of this group fail to respond to known neurohumours in reasonable concentrations, the nervous system is almost always diffusely spread in the tissue so that extracts cannot be prepared from it alone and, finally, in most of the responses of coelenterates which might be used for assay purposes it is not possible to specify the site of action of applied substances.

Previous work has been mainly on anemones; Ross (1945, 1952) found that the addition of alcoholic extracts of sea-anemone tissues to preparations of other anemones modified the responses of the latter to electrical stimulation, but concluded that either his extracts did not contain a chemical facilitator, or the chemical facilitator did not have the properties which he and Pantin had previously postulated (Ross \& Pantin, 1940). Being unable to make extracts of predominantly one cell type Ross could not know the histological origin of his active substances. Experiments with sea anemones are complicated by their phases of activity (Batham \& Pantin, I950a, $b$ ) and assays take a long time to perform, difficulties which are not experienced when effects on the rhythm of jellyfish are studied. Chemical analysis of tissues of anemones has also yielded little. An unidentified catecholamine is distributed in the tentacles of the anemones Metridium and Tealia in a way which suggests that it may be localized in nerve cells (Dahl, Falck, Mecklenburg \& Myhrberg, 1963).

The only relevant study on medusae is by Lenhoff (1964), who found in the mesogloea of the hydromedusan Aequorea aequorea a substance which inhibited the beat of the hydromedusan Stomotoca atra. There is no suggestion, however, that this substance is nervous in origin.

Jellyfish are the only coelenterate group with nervous tissue concentrated into discrete ganglia. Thus jellyfish rhopalia (where the ganglia are situated) contain a much larger percentage of nervous tissue than can be obtained elsewhere in this phylum. Jellyfish also have a readily observed activity, the spontaneous beat, which is directly under the control of the nervous system (Romanes, I876), so that effects on the rhythm are likely to be effects on nerve cells. 


\section{MATERIALS AND METHODS}

The jellyfish Aurelia aurita L., Cyanea capillata L. and Cyanea lamarcki Peron \& Lesueur, used in this study, were caught in large numbers on the west coast of Scotland in Loch Leven during June and July, and on the east coast in St Andrews Bay during August and September. They survived without feeding for periods of up to 2 weeks in tanks in the laboratory, provided these tanks had a slow flow of sea water through them and an outlet protected by nylon gauze. Only those animals with a strong beat and an unbroken margin were used. The hydromedusan Phialidium hemisphericum L., also used as an assay preparation in a few experiments, was caught in plankton hauls in St Andrews Bay during October and November. Specimens survived for several days in open dishes that had a constant supply of aerated sea water passing through them.

The jellyfish used have eight marginal ganglia, each of which is associated with a calcareous statolith. The statoliths are easily visible as dark spots about $0.5 \mathrm{~mm}$. diameter in the otherwise transparent margin. The whole ganglion occupies several cubic millimetres and electron micrographs show that here the ectoderm contains a high concentration of nerve fibres and cells (Horridge \& Mackay, 1962).

Pieces of tissue of about $10-20 \mathrm{~mm}^{3}$, each including a ganglion, were dissected out and immediately dropped into a specimen tube containing 'Analar' acetone. From measurements of sections the pieces were roughly estimated as being 10-20\% nervous tissue, the rest being mesogloea, endoderm, and ectoderm tissue. A known number of ganglia, usually 100 , were stored in each tube at a temperature of $-20^{\circ} \mathrm{C}$. Ganglia from different species of jellyfish were kept separate.

\section{Preparation of extracts}

Ganglia were pulverized for $5 \mathrm{~min}$. in the acetone in which they were stored and the suspension was then centrifuged. Following preliminary experiments which showed it to be pharmacologically inactive, the residue was discarded, while the supernatant was evaporated to dryness, in vacuo, below $30^{\circ} \mathrm{C}$. The residue after evaporation was redissolved in 'Analar' acetone, the insoluble part rejected, and the solvent again evaporated to dryness. This process was necessary to remove water-soluble but acetone-insoluble substances which were introduced with the water contained in the tissue. The dry residue was then dissolved in filtered boiled sea water. For chromatography the dry extracts were dissolved in acetone. In preliminary experiments, a variety of other extraction solvents, including ethanol, $0 . \mathrm{IN}-\mathrm{HCl}$ and sea water were tested but found to be less effective.

Extracts of tentacles and other non-nervous jellyfish tissue were prepared in the same way and used for comparison. Some, containing ectoderm and mesogloea, were taken from the exumbrellar surface; others, from Cyanea lappet tissue, contained endoderm, ectoderm and mesogloea. These various tissues have individual limitations as controls because the statolith, the pigment spot (in Aurelia only), as well as the nervous tissue are all present only in the ganglion. In addition, the proportions of endoderm, mesogloea and non-nervous ectoderm in the control tissue may differ from those in the marginal ganglia. However, one must take what is available, and the ganglia certainly contain the most nervous tissue. 


\section{The assay preparation}

A segment, by which is meant the peripheral part of a $45^{\circ}$ sector of a jellyfish, bearing a single ganglion, will beat continuously for several days in a dish of aerated sea water (Romanes, 1877). About $3 \mathrm{hr}$. after isolation the number of beats per minute may become relatively constant and the intervals between beats more or less equal. Following earlier experience with this preparation (Horridge, 1959) a segment was considered suitable as an assay preparation when it displayed this regular beat.

Beats of the jellyfish segment were recorded by a standardized kymograph technique, as illustrated in Fig. I. The segment was connected to the recording lever by means of a hair which was attached to one end of the segment by a hook, the other end of the segment being pinned to the wax in the dish. The extracts were added to a small aerated depression in the wax surrounding only the marginal ganglion, which was isolated from the sea water in which most of the preparation floated.

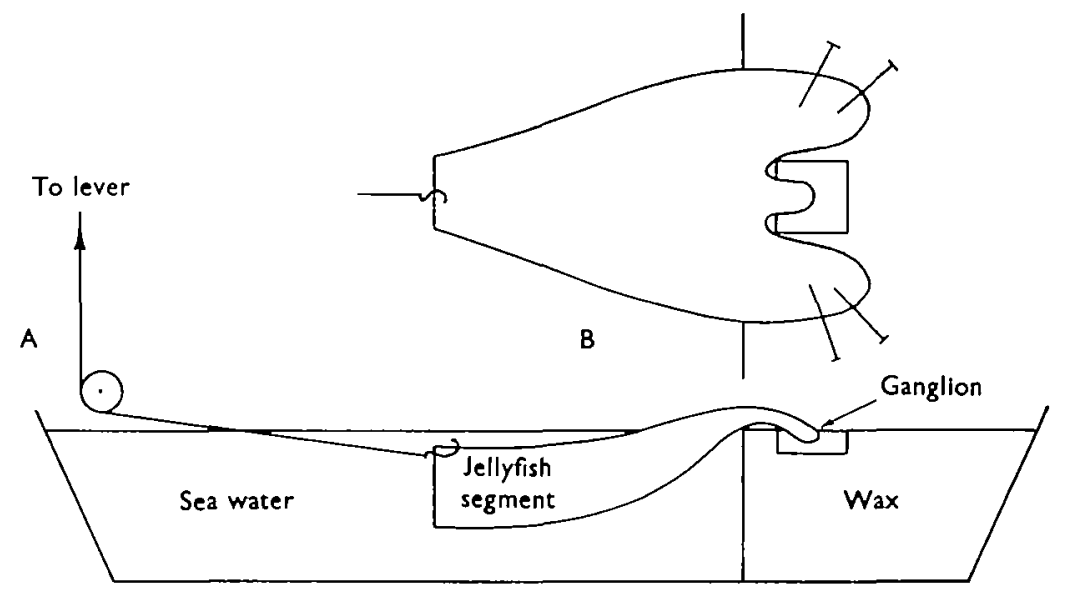

Fig. I. A single-segment preparation of Cyanea capillata as arranged for kymograph recording. The sea water immediately surrounding the ganglion is aerated contınuously but, for clarity, the aeration tube has been omitted. A, Side view; B, plan. The dish $1823 \mathrm{~cm}$. $\times 19 \mathrm{~cm}$. $\times 4 \mathrm{~cm}$.

When used as assay preparation the hydromedusan Phialidium was placed in I $\mathrm{ml}$. of aerated sea water or in the appropriate extract dissolved in sea water. Each beat was observed visually and its instant recorded as a stroke on moving paper.

\section{Chromatography}

One-dimensional ascending chromatograms were run on Whatman no. I paper with tert.-butanol-methanol-water, 40:50:10 by volume as solvent (Kerkut \& Laverack, 1960). The runs were carried out overnight in a tank 20 in. $\times 8$ in. $\times 20$ in. at $14^{\circ} \mathrm{C}$. with 10 in. to $\mathrm{I} 2$ in. of solvent flow. The atmosphere in the tank was saturated with solvent vapour before chromatograms were run. Extracts were run against standards including a number of amines, amino acids and substances known or likely to be present in coelenterates, or pharmacologically active in other animals.

Strips of different $R_{F}$ ranges were cut from chromatograms of ganglion extracts. 
Substances were eluted from these into minimum quantities of acetone which were then evaporated away. The dry residues were redissolved in I ml. quantities of sea water and successively assayed by the same method as before.

\section{RESULTS}

\section{Effects of extracts on single segments of jellyfish}

After allowing it to settle down, the rhythm of a beating segment was recorded for ro-20 min. The sea water in the small wax depression surrounding the ganglion was then replaced by a known concentration of an extract dissolved in sea water. After recording the rhythm during a series of ten 2 min. periods (for Cyanea segments) or ten I min. periods (for Aurelia segments, which beat more quickly), the extract was flushed out and the depression was refilled with clean sea water for a similar period of recording. This procedure takes into account the natural variability of the rhythm. The process was then repeated with the same or with a different extract. By repeated application of the same extract the effects of adding and removing an extract could be distinguished from possible spontaneous or extraneous disturbances of the rhythm. All experiments were carried out in a constant-temperature room, between I $^{\circ}$ and $13^{\circ} \mathrm{C}$. Separate experiments showed that temperature differences of this order had no effect on the results.

Ganglion extracts in concentrations of less than 50 ganglia $/ \mathrm{ml}$. had no consistent effect on the rhythm of the single-segment preparation as tested statistically by White's rank-order method (Edwards, 1954). When extracts of Aurelia ganglia at these concentrations were tested on Aurelia segments, seven out of seventeen experiments showed a statistically significant acceleration of the beat (at $5 \%$ level or better) upon addition of the extract; in two experiments the rate of beat decreased significantly, while in the remaining eight repetitions of the experiment there was no significant change. The tendency was to find increases at the lower concentrations and decreases at higher ones. The acceleratory effect of the extract in a typical experiment is illustrated in Fig. 2. When Aurelia ganglion extract at the same concentrations was tested on Cyanea segments there was a statistically significant acceleration of the beat in only two out of ten experiments, the remainder showing no change.

With higher concentrations of Aurelia ganglia extract (33-100 ganglia/ml.) assayed on Cyanea the rate decreased, sometimes to zero, when the extract was added and increased again on its removal, as shown in Table I and illustrated in Fig. 3 A and $B$. With extracts of non-nervous tissue at comparable or greater concentrations no change ever occurred. As pointed out in the discussion these effects are the opposite of those for lower concentrations. The effects of extracts of Cyanea ganglia at 50-100 ganglia/ml. were less definite. Extracts of Cyanea tentacles assayed on segments of Cyanea had variable, sometimes substantial, effects. For the later argument it is important to stress that the extracts affected only the rate of rhythm, and, in particular, did not cause tentacle contraction.

These preliminary tests indicate that at least one pharmacologically active substance is present in the Aurelia ganglion extract, justifying further analysis.

Chromatograms of acetone extracts of 300 Aurelia ganglia were divided into strips of different $R_{F}$ range; the eluates from these strips were separately assayed on a 


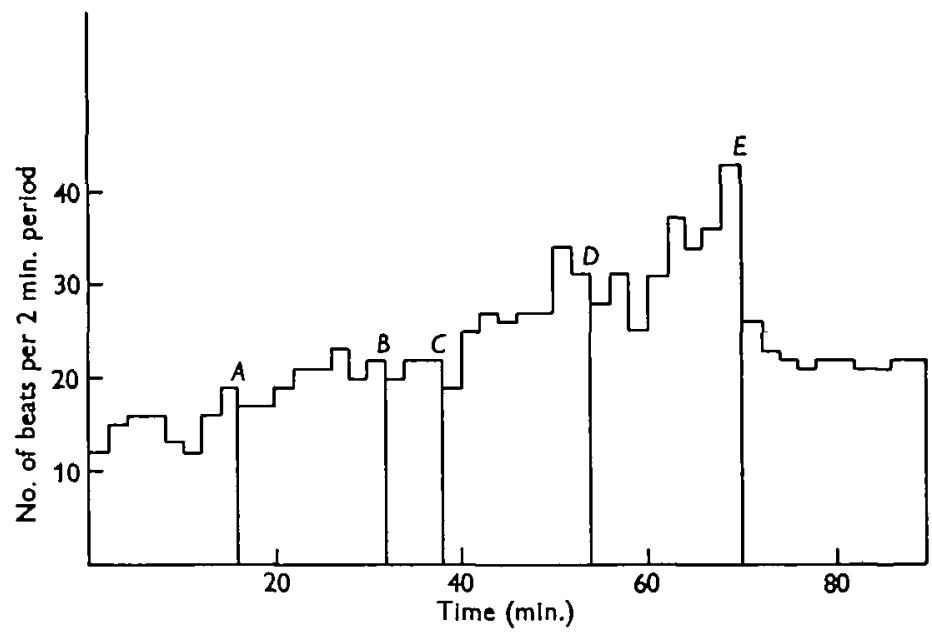

Fig. 2. Data from one experiment showing a consistent and reversible effect of low concentrations of acetone extracts of Aurelsa marginal ganglia on the pulsation rate of an intact ganglion of Aurelia. A, Addition of ganglia extract (concentration $0.5 \mathrm{ganglia} / \mathrm{ml}$ ) to a ganglion originally in sea water; $B$, further extract added (concentration now $1 . \circ$ ganglia $/ \mathrm{ml}$.); $C$, further extract added (concentration now 2.0 ganglia $/ \mathrm{ml}$.); $D$, further extract added (concentration now $3^{\circ} \circ \mathrm{ganglia} / \mathrm{ml}$ ) ; $E$, return to sea water.

\section{Table $\mathrm{I}$. Changes in rate of beat of jellyfish segments when immersed in extracts of jellyfish tissues}

Extract concen-

tration measured

in nos. of ganglia per $\mathrm{ml}$.

or g. wet wt.

non-nervous

extract per $\mathrm{ml}$.

Effect upon addition of extract

\section{Effect upon subsequent} removal of extract

(a) Aurelia ganglion extract, on segment of Cyanea

$\begin{array}{rll}33 & \text { Decrease 5\% sig. } & \text { Increase not sig. } \\ 33 & \text { Decrease I \% sig. } & \text { Increase I \% sig. } \\ 50 & \text { Decrease I \% sig. } & \text { Increase not sig. } \\ 50 & \text { Decrease I \% sig. } & \text { Increase I \% sig. } \\ 100 & \text { Decrease } 5 \% \text { sig. } & \text { Increase I \% sig. } \\ 100 & \text { Decrease I } \% \text { sig. } & \text { Increase I \% sig. } \\ 1 \infty & \text { Decrease not sig. } & \text { Increase I \% 81g. }\end{array}$

(b) Cyarea ganglion extract, on segment of Cyanea 50 Decrease not sig.

Increase not sig.

(c) Aurelia non-nervous tissue extract, on segment of Cyanea
$1 \cdot 25 \mathrm{~g}$.
No change
No change
$1 \cdot 25 \mathrm{~g}$.
No change
No change
I.25 g.
No change
Decrease I \% s1g.

(d) Cyamea non-nervous tissue extract, on segment of Cyanea
$0.5 \mathrm{~g}$.
No change
Decrease $5 \%$ sig.
$0.5 \mathrm{~g}$.
Increase $5 \%$ sig.
$0.75 \mathrm{~g}$.
No change
Decrease not sig.
$0.75 \mathrm{~g}$.
No change
No change
No change

The two species of Cyanea were not separated in this table because no differences could be observed between them. The significances were measured by White's rank-order test. 
jellyfish single-segment preparation at an approximate concentration of $25 \mathrm{ganglia} / \mathrm{ml}$. assuming a $50 \%$ loss of material during chromatography and elution. All effects were treated statistically. The results, summarized in Table 2 , show that the eluates from the $R_{F}$ range $0.8-0.9$ and $0.8-1 \cdot 0$ more frequently increase the rate than do eluates from any of the other $R_{F}$ ranges. A Wilcoxan paired rank test (Edwards, 1954)
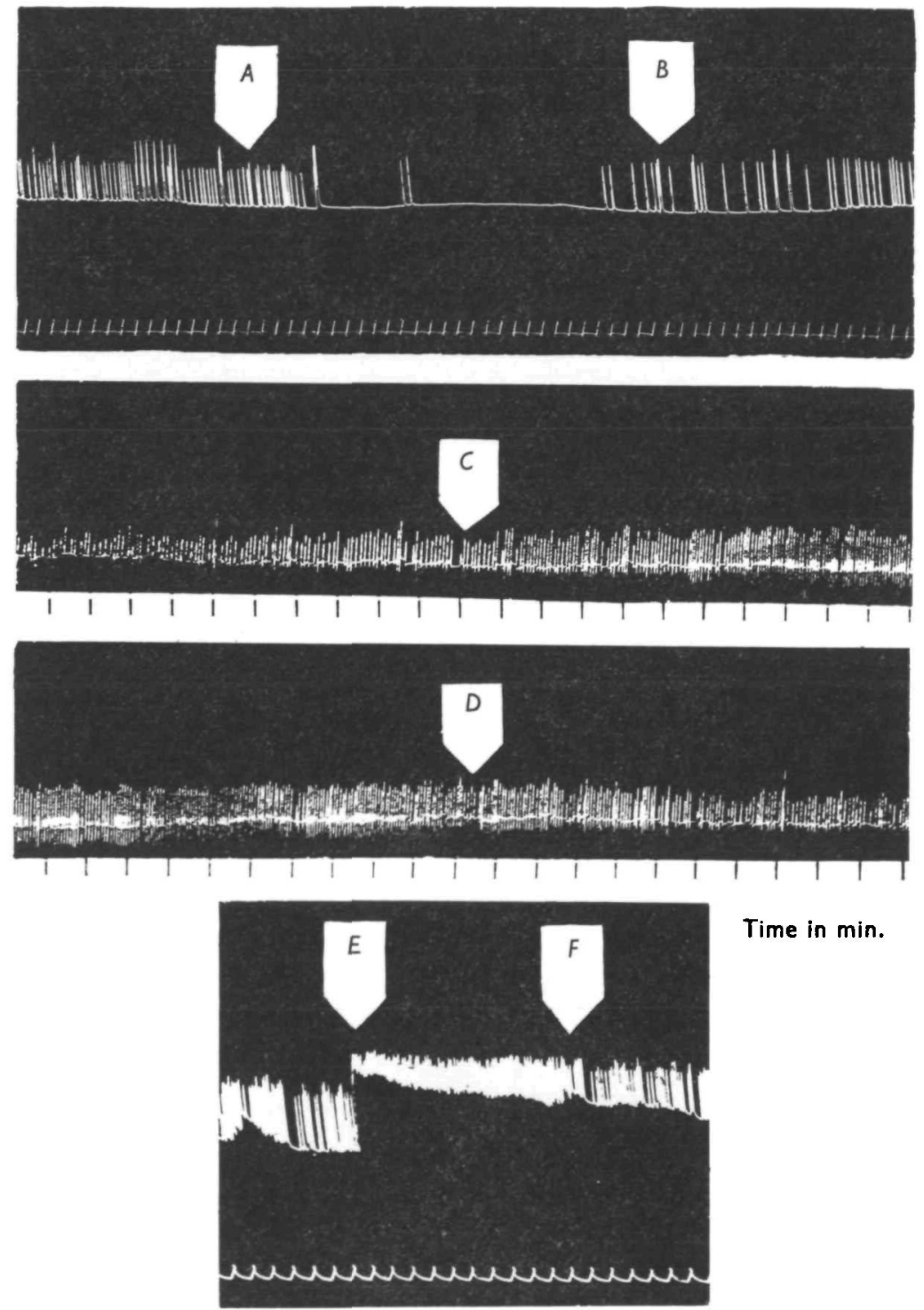

Time in $\min$.

Fig. 3. Records of effects of acetone extracts of Aurelia ganglia on the pulsation rate of segments of Cyanea and Aurelia. A, Addition of Aurelia whole-ganglion extract at concentration $50 \mathrm{ganglia} / \mathrm{ml}$. on the rhythm of a $C$ yanea segment; $B$, return to sea water; $C$, effect of eluate from $R_{F}$ range 0.8-1.0 of a chromatogram of Aurelia ganglion extract at a concentration of 25 ganglia/ml. approx. on the rhythm of an Aurelia segment; $D$, continuation of $C$, showing the effect of the return to sea water; $E$, addition of eluate from $R_{p}$ range $0.8-0.9$ of chromatogram of ganglia extract (concentration $25 \mathrm{ganglia} / \mathrm{ml}$. approx.) on a segment of Cyanea; $F$, return to sea water. 
on totalled results shows that the increase in rate is significant at the $5 \%$ level when Aurelia is used as the assay preparation, and at the $6 \%$ level when Cyanea is used. Results are based on ten chromatograms; altogether over 5000 ganglia were required.

Table 2. Effects of eluates from differing $R_{F}$ ranges of chromatograms of Aurelia ganglia extracts as measured on the rhythm of segments of Aurelia and Cyanea

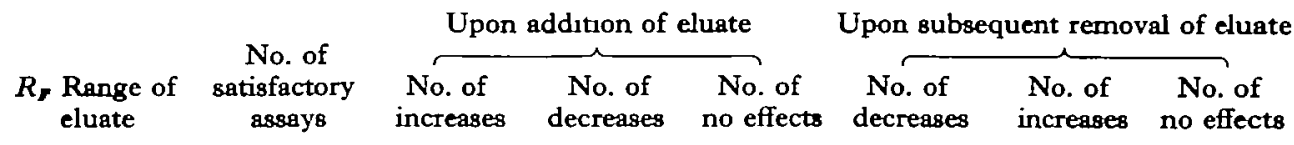

(a) Cyanea as assay preparation

$\begin{array}{rlllllll}0-0.1 & 6 & 1 & 1 & 4 & 0 & 1 & 3 \\ 0.1-0.2 & 6 & 2 & 2 & 2 & 2 & 0 & 4 \\ 0.2-0.3 & 6 & 1 & 0 & 5 & 3 & 0 & 3 \\ 0.3-0.4 & 6 & 1 & 0 & 5 & 1 & 0 & 5 \\ 0.4-0.5 & 6 & 0 & 0 & 6 & 1 & 0 & 5 \\ 0.5-0.6 & 5 & 0 & 0 & 5 & 1 & 0 & 4 \\ 06-0.7 & 5 & 1 & 1 & 3 & 1 & 1 & 3 \\ 0.7-0.8 & 5 & 1 & 0 & 4 & 2 & 1 & 2 \\ 0.8-0.9 & 5 & 3 & 0 & 2 & 1 & 0 & 4 \dagger \\ 0.9-1.0 & 5 & 0 & 1 & 4 & 0 & 0 & 4\end{array}$

(b) Aurelia as assay preparation

$\begin{array}{rrrrrrrr}0-0.1 & 7 & \text { I } & 0 & 6 & 2 & 0 & 5 \\ 0.1-0.2 & 8 & 2 & 2 & 4 & 4 & 1 & 3 \\ 02-0.3 & 10 & 1 & 1 & 8 & 1 & 1 & 8 \\ 0.3-0.4 & 10 & 3 & 0 & 7 & 0 & 0 & 10 \\ 0.4-0.5 & 10 & 2 & 1 & 7 & 4 & 0 & 6 \\ 0.5-0.6 & 11 & 1 & 2 & 8 & 1 & 0 & 10 \\ 0.6-0.7 & 11 & 2 & 2 & 7 & 3 & 0 & 8 \\ 0.7-08 & 7 & 0 & 1 & 6 & 0 & 0 & 7 \\ 0.8-10 & 15 & 7 & 1 & 7 & 3 & 1 & 10 * \pm\end{array}$

The two species of $C y$ anea are not separated in this table because no differences could be observed between them. All increases or decreases so counted were significant at the $5 \%$ level by White's rankorder test (Edwards, 1954). Significance of the increase or decrease 18 based upon comparisons of numbers of beats before and after addition and subsequent removal of extracts, as described earlier.

- The discrepancy between the number of assays where the eluate is added and the number where the eluate is subsequently removed is due to failure to remove extract in some cases.

$\dagger$ When all results with eluates from this $R_{\text {r }}$ range are considered together, the change in rate in the appropriate direction is significant at the $6 \%$ level using a Wulcoxan parred rank test.

I When all results with eluates from this $R$, range are considered together, the change in rate in the appropriate direction is significant at the $5 \%$ level using a Wilcoxan paired rank test.

\section{Other assay preparations}

Extracts of Aurelia ganglia in concentrations of $33-5^{\circ}$ ganglia $/ \mathrm{ml}$. have a strong effect on the rate at which Phialidium pulsates. In five experiments this effect was an acceleration of the beat, which decreased again to normal following the return to sea water. In two experiments, both with one particular preparation, the effect was a reversible decrease in the pulsation rate. In five of these experiments the change was significant at the I \% level using White's rank test, in one at the $5 \%$ level, and in one at the $6 \%$ level. The effects of extracts of non-nervous tissue from Aurelia were less definite and usually not significant; Cyanea tentacle extracts kill Phialidium.

No other assay preparation was found to be particularly sensitive to Aurelia ganglion extract. Amongst those tested were crab and clam hearts and crustacean hind-gut. 


\section{Chemical tests on extracts}

Chromatograms of extracts were viewed under ultraviolet light and tested with a variety of standard spot reagents (Dawson, Elliott, Elliott \& Jones, I959). In addition, known substances were run alongside the extracts, including adrenaline, noradrenaline, dopamine, dihydroxyphenylalanine, acetylcholine, tetramethylammonium bromide, 5-hydroxytryptamine, tryptamine, histamine, tyramine and several amino-acids. Some of these substances have been found in sea anemones(Mathias, Ross \& Schachter, I960).

The only consistent property of the substance which occurs on chromatograms of Aurelia ganglion extracts in the active region was its white fluorescence in ultraviolet light. The fluorescent substance had $R_{F}$ values of $0.88,0.80,0.82,0.85$ (3 times), and 0.87 on seven chromatograms on which it was examined. Though it did not stain with ninhydrin on two chromatograms, there was a slight indication of staining on a third. It stained yellow with Ehrlich's reagent (indicating aromatic amine) on one chromatogram though not on another. Diazotized $p$-nitraniline and diazotized $p$ bromoaniline, which also detect aromatic amines, showed nothing. The staining properties and $R_{F}$ values were different from those of all the standards run. Thus this substance is unlikely to be the catecholamine found by Dahl et al. (1963) in the tentacles of sea anemones, and very little positive information is forthcoming as to its properties. It is unlikely to be an indole as it did not stain purple with Ehrlich's reagent, nor a phenol as it did not stain with $p$-nitraniline, nor a choline ester as it did not stain with hydroxylamine-ferric chloride, nor a saturated fat as it showed fluorescence before being stained. As it ran to a high $R_{F}$ in a highly polar solvent, it might have been a polar substance of low molecular weight, but lipids also run to a high $R_{F}$ in this solvent. On chromatograms of Cyanea ganglia extracts another substance occurring in this $R_{F}$ range showed yellow fluorescence in ultraviolet light. In two chromatograms of Cyanea tentacle extracts there were, in addition, distinct spots with white fluorescence. Compounds with yellow fluorescence occurred in this $R_{F}$ range on chromatograms of non-nervous and tentacle tissue of both Cyanea and Aurelia. One must also bear in mind that the active substance thought to occur in this $R_{F}$ range might not have been detected by any reagent, the fluorescent spots being due to another substance with the same $R_{F}$ value.

The same tests showed the presence of substances at $R_{F}$ values other than $0.8-0.9$, but, as they had no pharmacological activity, they are of little relevance. It may be noted, however, that a yellow pigment ran to $R_{F} 0.6$ on chromatograms of Aurelia ganglion extract, and a spot near $R_{F} O \cdot \mathrm{I}$ in the same extract could be a peptide as it consistently stained purple with ninhydrin and green with Folin's reagent.

Attempts were also made to obtain the infrared and ultraviolet absorption spectra of eluates in the $R_{F}$ range $0.8-0.9$ from Aurelia ganglion extracts. The infrared spectrum revealed nothing; the ultraviolet spectrum did, however, show a small peak in the range $270-280 \mathrm{~m} \mu$. This could be the substance with fluorescence on the paper. The peak was accentuated by increasing the $\mathrm{pH}$ to $\mathrm{I} 2$ and by decreasing it to 2 , indicating an amphoteric compound. A more detailed analysis is necessary before the compound can be identified. 
DISCUSSION

The presence of an active substance of some kind in Aurelia ganglia eluates in the $R_{F}$ range $0.8-0.9$ seems definite. The acceleratory effects obtained with these eluates are similar to those obtained where low concentrations of whole extract are used, in contrast to the decreases that occur when high concentrations (50-100 ganglia/ml.) of extract are used. The spontaneous activity of jellyfish is frequently inhibited by overstimulation although accelerated by gentle mechanical stimulation. Possibly the pharmacologically active substance is normally excitatory in function, though in high concentration it is inhibitory.

Apart from the fact that many possibilities have been eliminated little can be said about the active compound. None of the known neurohumours corresponds in colour reaction or $R_{F}$ value with the active substance. Of other organisms tested as assay preparations only the hydromedusan Phialidium is sensitive to Aurelia ganglia extract. Coelenterates evidently diverge widely from other groups in not being sensitive to the commonly occurring neurohumours and in producing substances which are active only on the coelenterates themselves. The controls used in these experiments are unavoidably not as perfect as might be desired. We cannot with certainty state that the pharmacologically active substance originates from nervous tissue, although the main difference between the ganglia and the control tissues lay in the amount of nervous tissue. The controls rule out the possibility, however, that the substance is the inhibitory mesogloeal substance found by Lenhoff (1964) in the hydromedusan Aequorea.

Although the jellyfish ganglion is the simplest example of a central nervous system, several interrelated parts can already be distinguished, and further complexity may appear. Fig. 4 is a diagram of a part of a hypothetical jellyfish marginal ganglion and associated structures as inferred from earlier work (Romanes, 1877 ; Horridge, $1956 a$, $b$, 1959; Passano \& McCullough, 1960). The structures numbered are sites which may be sensitive. Extracts of ganglia could have an acceleratory effect by acting at any of the sites shown, with the exception of the neuromuscular junctions (8), and the muscle membranes (9), both of which are situated outside the ganglion and therefore would not come into contact with the extracts. In particular, an acceleration of the rhythm could be an effect directly on the pacemaker, or indirectly on the diffuse sensory nerve net. The ganglion extracts have no effect on de-ganglionated segments of Aurelia. On the single piece of evidence that the extracts do not cause tentacle contraction we infer that the diffuse nerve net was not stimulated. The pacemaker is therefore the most likely point of action of the active component of the extract, but other less probable interpretations can be made, especially if the ganglion is morphologically more complex than we now suppose.

The cytological origin of the active substance is also unknown, though electron microscope studies on jellyfish marginal ganglia show that vesicles occur abundantly in the sensory neurones and are concentrated at both sides of synaptic contacts (Horridge \& Mackay, 1962). However, there is no physiological evidence that rapid transmission at synapses in coelenterates is chemical in nature or that neurosecretion occurs. The pacemaker in the ganglion is slow, because intervals between the beats can be as long as $5 \mathrm{sec}$. or even $2 \mathrm{~min}$. We conclude that the extracted chemical may be involved in the control of the rhythm but only direct micromethods can test this. 


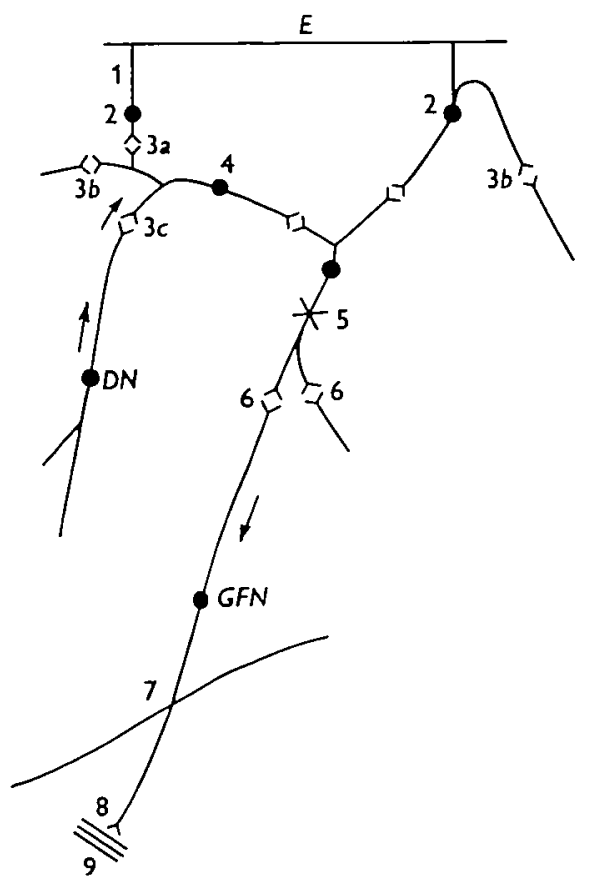

Fig. 4. Elements of jellyfish marginal ganglion and associated structures. Sensory cells are not clearly distinguishable from 'interneurones', whuch again are not clearly distinguishable from diffuse net neurones. I, Receptor of sensory neurone; 2 , cell body of sensory neurone; $3 a$, sensory neurone-to-' interneurone'synapse, $3 b$, 'Interneurone'-to-' interneurone' synapse; $3 c$, diffuse net fibre to 'interneurone' synapse; 4, 'interneurone' cell body; 5, pacemaker; 6 , 'interneurone' to giant fibre synapse; 7 , giant fibre to giant fibre synapse; 8 , neuromuscular junction; 9 , muscle membrane; $D N$, diffuse net; $E$, ectodermal epithelium of ganglion; $G F N$, giant fibre net. Synapses of types 6 and 7 are presumed to be two-way but there must be oneway synapses between the diffuse net and the pacemaker region.

\section{SUMMARY}

I. A substance which is extractable with acetone from the marginal ganglia of the jellyfish Aurelia causes acceleration of the rhythm of intact ganglia used as test preparations in concentrations of under $5^{\circ}$ ganglia $/ \mathrm{ml}$, while higher concentrations cause inhibition. As comparable extracts of non-nervous tissue had no effect, the active substance probably originates from nervous tissue. It is distinct from substances extractable from mesogloea.

2. The $R_{F}$ lies near 0.85 in tert.-butanol-methanol-water (40:50: ro by vol.). The chemical nature of the acceleratory substance is unknown though it is certainly none of the known or suspected neurohumours of other organisms.

3. The active substance has no effect on crustacean or clam hearts or upon crustacean hindgut assay preparations but it does accelerate the rhythm of a hydromedusan Phialidium.

This research was made possible by a grant from the Browne Fund of the Royal Society to one of the authors and by a vacation grant from the Carnegie Foundation to the other. We would like to thank Miss D. Rutherford and Mr S. Kulik for their assistance with the numerous assays. 


\section{REFERENCES}

Batham, E. J. \& Pantin, C. F. A. (1950a). Inherent activity in the sea anemone, Metridium senile (L.). 7. Exp. Buol. 27, 290-301.

Batham, E. J. \& Pantin, C. F. A. (1950b). Phases of activity in the sea anemone, Metrudium senile (L.), and their relation to external stimuli. F. Exp. Biol. 27, 377-99.

Dahl, E., Falck, B., MecklenbuRg, C. von \& MYhrberg, H. (1963). An adrenergic nervous sybtem in sea anemones. Quart. F. Micr. Sci. ro4, 531-4.

Dawson, R. M. C., ElliotT, D. C., ElliotT, W. H. \& Jones, J. M. (1959). Data for Biochemical Research. Orford.

EDwards, A. L. (1954). Statistical Methods for the Behavioral Sciences. New York: Holt, Rinehart and Winston.

Horridge, G. A. (1956a). The nervous system of the ephyra larva of Aurellia aurita. Quart. F. Muct. Sci. $97,59-74$.

Horridge, G. A. (1956b). The nerves and muscles of medusae. V. Double innervation in Scyphozoa. F. Exp. Biol. 33, 366-83.

Horridge, G. A. (1959). The nerves and muscles of medusae. VI. The rhythm. F. Exp. Biol. 36, 72-91.

HorRmGe, G. A. \& MACKAy, B. (1962). Naked axons and symmetrical synapses in coelenterates. Quart. F. Micr. Sci. 103, 531-41.

KeRKUT, G. A. \& LaAverack, M. S. (Ig60). A cardio-accelerator present in tissue extracts of the snail Helix aspersa. Comp. Biochem. Physiol. r, 62-71.

LENHOFF, H. M. (1964). Reversible inhubition of swimming in Stomatoca alba by mesogleal extracts of some other medusae. Biol. Bull., Woods Hole, 126, 1 1 5-20.

Mathias, A. P., Ross, D. M. \& Schachter, M. (I960) The distribution of 5-hydroxytryptamine, tetramethylammonium, homarine and other substances in sea anemones. F. Physiol. 15I, $296-311$.

Passano, L. M. \& McCullough, C. B. (1960). Nervous activity and spontaneous beating in scyphomedusae. Anat. Rec. 137, 387.

Romanes, G. J. (1876). Preliminary observations on the locomotor system of medusae. Phul. Trans. B, I66, 269-313.

Romanes, G. J. (1877). Further observations on the locomotor system of medusae. Phil. Trans. B, I67, 659-752.

Ross, D. M. (1945). Facilitation in sea anemones. II. Tests on extracts. F. Exp. Biol. 22, 32-6.

Ross, D. M. (I952). Facilitation in sea anemones. III. Quick responses to single stumuli in Metridium senile. F. Exp. Brol. 29, 235-54.

Ross, D. M. \& Pantin, C. F. A. (1940). Factors influencing facilitation in Actinozoa. The action of certain ions. F. Exp. Biol. 17, 61-73. 